ISSN $0819-2642$

ISBN 9780734032836

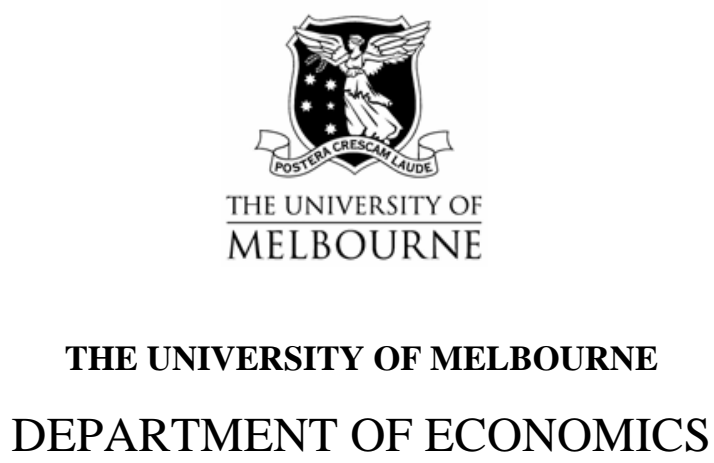

RESEARCH PAPER NUMBER 1048

August 2008

\title{
Abolishing the Tax-Free Threshold in Australia: Simulating Alternative Reforms
}

by

John Creedy, Nicolas Herault \& Guyonne Kalb

Department of Economics The University of Melbourne Melbourne Victoria 3010 Australia. 


\title{
Abolishing the Tax-Free Threshold in Australia: Simulating Alternative Reforms*
}

\author{
John Creedy\#, Nicolas Hérault\#\# and Guyonne Kalb\#\# \\ \# Department of Economics \\ The University of Melbourne \\ and \\ \#\#Melbourne Institute of Applied Economic and Social Research \\ The University of Melbourne
}

August 2008

\begin{abstract}
This paper examines the role of the tax-free income tax threshold in a complex tax and transfer system consisting of a range of taxes and benefits, each with their own taper rates and thresholds. Considering a tax and benefit system with benefit taper rates whereby some benefits are received by income groups other than those at the bottom of the distribution, it is suggested that a tax-free threshold is not a necessary requirement to achieve redistribution. Four alternative policy changes, each involving the elimination of the tax-free threshold in Australia and designed to achieve approximate revenue neutrality, were examined using the Melbourne Institute Tax and Transfer Simulator. A range of implications were examined, including labour supply responses to tax changes, and the effects of policy changes on inequality and social welfare. The results demonstrate that it is possible to eliminate the tax-free threshold under approximate overall revenue and distribution neutrality, but that it is impossible to improve labour supply incentives at the same time. In order to achieve improved incentives, either revenue or distribution neutrality has to be sacrificed.
\end{abstract}

\footnotetext{
${ }^{*}$ We are grateful to Norman Gemmell for prompting us to examine tax reforms involving elimination of the tax-free threshold in Australia, and Rienk Asscher for comments on an earlier draft. An early version of the paper was presented at the 2008 Econometric Society Australasian Meeting in Wellington, New Zealand.
} 


\section{Introduction}

This paper reports behavioural microsimulation results for several tax policy reforms in which the Australian tax-free threshold is eliminated and adjustments to tax rebates, as well as marginal income tax rates, are made. The reforms include a flattening of the income tax rate structure, which is often suggested by those who are in favour of cutting the tax-free threshold. The simulations allow for potential labour supply responses using the Melbourne Institute Tax and Transfer Simulator (MITTS). ${ }^{1}$ A range of inequality and welfare effects are reported. Such simulations can contribute to rational policy analysis in view of the considerable population heterogeneity and the impossibility of knowing a priori how individuals will respond to policy changes. Information about likely quantitative orders of magnitude is crucial and, as demonstrated here, labour supply effects may be substantial. The alternative structures examined concentrate on revenue-neutral comparisons. Simply eliminating a tax-free threshold without introducing complementary adjustments to other features of the tax structure would have undesirable budgetary and distributional impacts. ${ }^{2}$ Without imposing revenue-neutrality, alternative policies cannot be properly compared. ${ }^{3}$

A tax-free threshold, below which the income tax rate is zero, is a feature of many tax systems and was initially motivated largely by equity considerations. However, this feature is not required in an integrated tax and transfer structure. Those countries without a taxfree threshold usually have some kind of tax rebate to deal with distributional objectives for low-income households and individuals. The simultaneous payment of income tax and receipt of benefits is a common feature of modern tax and transfer systems. Indeed this can only be avoided by introducing a tax-free threshold at a very high level. Although such a policy is supported by some commentators ${ }^{4}$, this could prove difficult to achieve in

\footnotetext{
${ }^{1}$ This is described briefly in Appendix $\mathrm{A}$ and in detail in Creedy et al. (2002). Creedy and Kalb (2006) describe some of the more recently introduced features of MITTS, and Kalb and Lee (2007, 2008) report updated wage and labour supply estimates underlying the labour supply responses in the behavioural simulations.

${ }^{2}$ This statement, as in many policy debates, clearly attaches much weight to the status quo, whereby the existing sytem is implicitly judged to have desirable properties.

${ }^{3}$ For example, Saunders (2006, p. xxvi) argues that, 'At the same time as the top marginal rate is reduced, the tax-free threshold should be raised to a level above the welfare minimum (subsistence) level ... it would mean that all taxpayers enjoyed a substantial tax cut'. He does not mention compensating changes to other forms of revenue or expenditure along with this revenue-reducing reform, so it is unclear how this policy change would be financed and what the impact of this alternative revenue-generating process would

${ }^{4}$ For example, Saunders and Maley (2006, p. 113) argue that, 'The principled case for raising the threshold is that workers should be allowed to earn and retain enough money to meet their own subsistence needs before any tax is taken away from them.' However, the principle involved (whether of a basic value judgement or an efficiency criterion) is not actually mentioned. A similar argument for raising the threshold
} be. 
a structure with many means-tested benefits involving benefit taper, or withdrawal, rates such that some benefits are not confined to the lower-income ranges. What really matters in a complex multi-tax and transfer structure is the overall redistributive effect. ${ }^{5}$ Raising the threshold in order to help low-income groups actually has a low 'target efficiency' in that it involves at least the same absolute gains by those subject to higher marginal tax rates. Different sides of the debate are clearly recognised in the summary by Freebairn (1998, p. 67 ), who suggested that,

Removing the tax-free threshold for many taxpayers would enable funding lower marginal tax rates, and hence lower efficiency costs. But equity concerns almost certainly will require the addition of a means tested threshold or grant. Withdrawal of the grant can only mean higher effective marginal rates, and greater distortions, for those on low and middle incomes. Given the distribution of tax payable with the present system, and stated intentions not to disadvantage those on low incomes, it is difficult to envisage a tax rate schedule without a tax-free threshold which is not regressive.

However, as the following analysis shows, careful consideration of practical design aspects of taxes and transfers, using a microsimulation model, makes it possible to achieve an elimination of the tax-free threshold which is both approximately distribution and revenue neutral, although marginal effective tax rates for middle to higher incomes are increased.

Few countries have adopted an income tax structure without a tax-free threshold. An exception is New Zealand. However, the use of personal allowances meant that there was an effective tax-free threshold from the introduction of the income tax in 1891 until 1972. There is now a relatively broad base, with a range of tax rebates for low incomes, a combination of different means-tested transfer payments and a progressive, or graduated, marginal income tax rate structure. For discussion of the tax reform changes in New Zealand, see Stevens (1990).

was made by Veit-Wilson (1999), who showed that in practice in the UK there had been no coordination between those responsible for tax thresholds and those responsible for setting benefit levels.

${ }^{5}$ An early clear statement of this view was made by Hicks (1946, p. 150) who dated its realisation from the last quarter of the 19th century: 'Instead of regarding each tax separately, and attempting the impossible task of choosing only those taxes which would pass all the tests, it was suddenly realized that any desired distributional result could be obtained by a compensatory structure of taxes, in which the faults of one would be offset by the virtues of another'. Hicks then made the point that expenditures, as well as taxes, also need to be taken into account. 
In Australia, where there has been limited indexation of tax thresholds over many years ${ }^{6}$, there have been calls to increase the tax-free threshold as a way of helping low-income groups. But, as mentioned above, such an increase gives at least the same benefits to higher-rate taxpayers. The question is how might elimination of the Australian tax-free threshold be achieved with minimal impacts on lower-income groups? One alternative may be to abolish the tax-free income range and replace this with a similar amount in rebates for lower income individuals. The remaining funds could be used to pay for a reduction in the middle income tax rates to compensate those on middle and higher incomes (outside of the range of the new rebate) at least partly. Such a policy change could be expected to result in labour supply effects, since high-level rebates extend further up the income scale and thus lead to higher effective marginal rates for all people who have income in the extended rebate withdrawal range. In addition, higher taxes are expected for middle to high income groups if the increase in tax base is not sufficient to allow tax rates to be reduced by a large enough amount to compensate each individual fully for the loss of the tax-free income range.

Determining a revenue-neutral policy change that abolishes the tax-free income range is complex, which is at least partly due to the difficulty of determining potential labour supply responses with a range of effects working in opposite directions. A proper analysis requires a microsimulation model to evaluate the hypothetical policy options and enable full inclusion of all aspects of the reform.

In order to clarify some features of a policy change involving elimination of the tax-free threshold, Section 2 considers a simplified tax and transfer system which however represents the main features of the Australian and other tax and transfer systems. The alternative policies are described in Section 3. Policy simulations for Australia are reported in Section 4, using the Melbourne Institute's behavioural microsimulation model MITTS. Conclusions are in Section 5 .

\section{Abolition of the Tax-Free Threshold in a Simplified Tax Structure}

Consider a simplified tax structure involving the taxation of individuals, as shown in Figure 1. The income tax involves a tax-free threshold of $a$, above which income is taxed at a fixed

\footnotetext{
${ }^{6}$ In Australia, no indexation has taken place from 2000/2001 up to 2003/2004, when the tax thresholds were increased slightly, and again in 2004/2005. In 2005/2006 and 2006/2007 larger increases were introduced, particularly for the top two tax thresholds. The tax-free income threshold has not changed since 2000/2001. Before the July 2000 change, there was no indexation over a long period.
} 
rate, $t$. There is a single benefit, or transfer payment, having a taper rate $s$, where $t<s<1$, and a range of 'free' income before the taper begins to apply. Furthermore, the receipt of the transfer payment extends beyond $y=a$. In Figure 1, the relationship between net (after tax and transfers) income and gross income is shown by the piecewise-linear schedule ABCD. The diagram concentrates on the lower ranges of the income distribution. To reduce the number of parameters involved, it is assumed that the taper-free range of the benefit is the same as the tax-free range of the income tax structure, equal to $a$. Although in practice, tax and transfer systems are usually highly complex, with numerous overlapping benefits, each with its own thresholds, the simple form shown in Figure 1 is a reasonable approximation which captures the issues relevant to a more complex system.

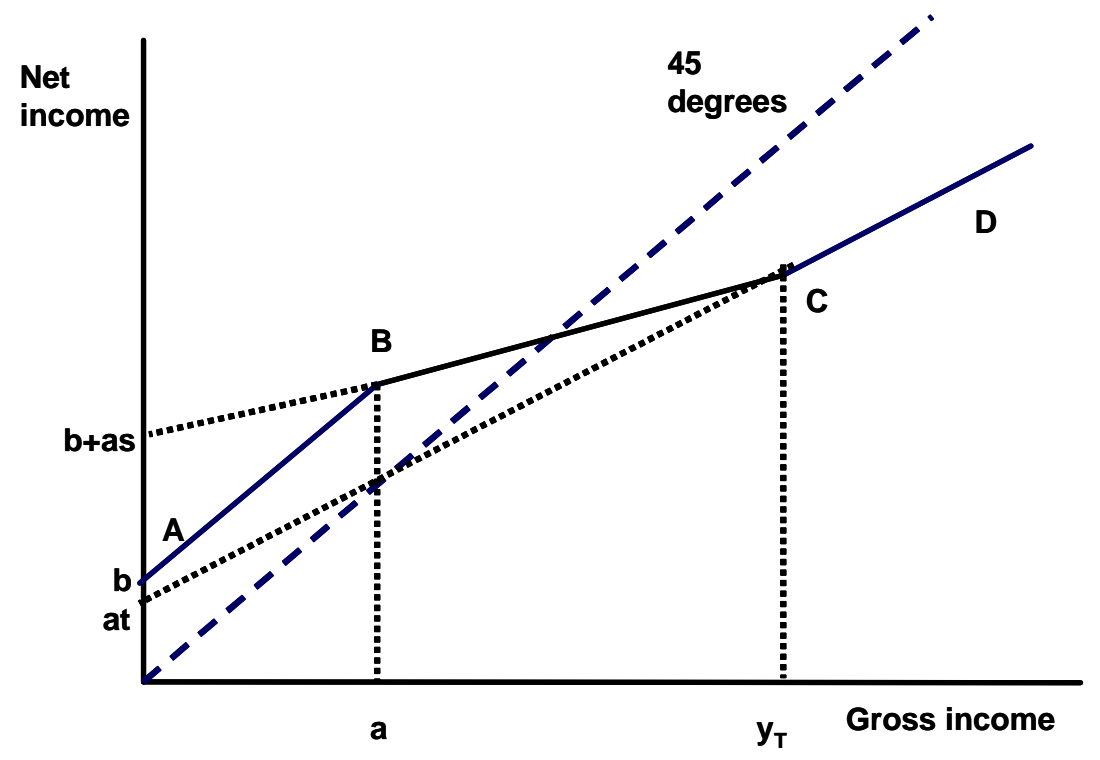

Figure 1: A Stylised Tax and Transfer System

In the pre-reform situation, suppose the benefit received when $y=0$ is equal to $B(0)=b$. As continuity is imposed on the relationship, the point B in Figure 1 must correspond to a net income of $z=a+b$. Furthermore the segment BC, when continued to the net income axis, must have an intercept of $b+a s .{ }^{7}$ The threshold income $y_{T}$, above which the means-tested benefit is exhausted and individuals only pay income tax, is given by:

$$
a t+(1-t) y_{T}=(b+a s+a t)+(1-s-t) y_{T}
$$

\footnotetext{
${ }^{7}$ This is because it must be the case that if $q$ is the intercept, $a+b=q+a(1-s)$, which can be solved for $q$.
} 
so that:

$$
y_{T}=\frac{b+a s}{s}
$$

For those between $\mathrm{B}$ and $\mathrm{C}$, the net transfer, defined as the difference between their net income $z$ and their income after the payment of income tax alone, is given by:

$$
\begin{aligned}
z-y & =\{b+a s+a t+(1-s-t) y\}-y \\
& =b-(s+t)(y-a)
\end{aligned}
$$

A reform involving the elimination of the tax-free threshold in the income tax would generate extra revenue. The latter could be used to reduce the income tax rate to $t^{\prime}$. In addition, a tax rebate could be introduced in order to maintain the section AB. Individuals, who previously paid no tax as they were below the tax-free threshold $a$, would need to receive a tax rebate of $t^{\prime} y$ up to a maximum of $t^{\prime} a$. The tax rebate would have a taper rate $s_{t r}$ applying above $a$. This taper rate can be chosen so that the tax rebate is exhausted at the same time as the benefit $b$ at threshold $y_{T} \cdot{ }^{8}$ This reform implies that individuals with gross income between $a$ and $y_{T}$ face a higher effective marginal tax rate than before; that is, people formerly subject to the means-tested taper rate $s$ now face an additional taper rate $s_{t r}$ corresponding to the withdrawal of the tax rebate. This system is shown in Figure 2. The point $\mathrm{C}$ moves downward to $\mathrm{C}^{\prime}$ due to the introduction of the new taper rate $s_{t r}$, which needs to be larger than the reduction in the income tax rate. Again the reform is not completely distribution-neutral. The overall effect on net income inequality is not obvious as it depends on the pre-tax income distribution.

Even in such stylised structures the condition required for revenue-neutrality is complex because of the nonlinearities involved, so that closed-form solutions for new parameter values, such as $t^{\prime}$, are not available. Furthermore, the labour supply implications of this type of piecewise-linear tax and transfer system are complex, particularly because of the nonconvexities in individuals' budget sets arising from the reduction in the effective marginal tax rate as entitlement to the means-tested benefit is exhausted. ${ }^{9}$ The overall effect is unclear a priori as it depends on the initial distribution of income and the balance of income and substitution effects. This reform involves a minimum of changes - adjusting $t$ while keeping net incomes of low-income individuals unchanged - and of course it would be possible to modify other parameters.

\footnotetext{
${ }^{8}$ This is not a necessary constraint but it limits the number of parameters involved.

${ }^{9}$ See Creedy and Kalb (2006, 2005a) for discussion of labour supply modelling in continuous and discrete hours models.
} 


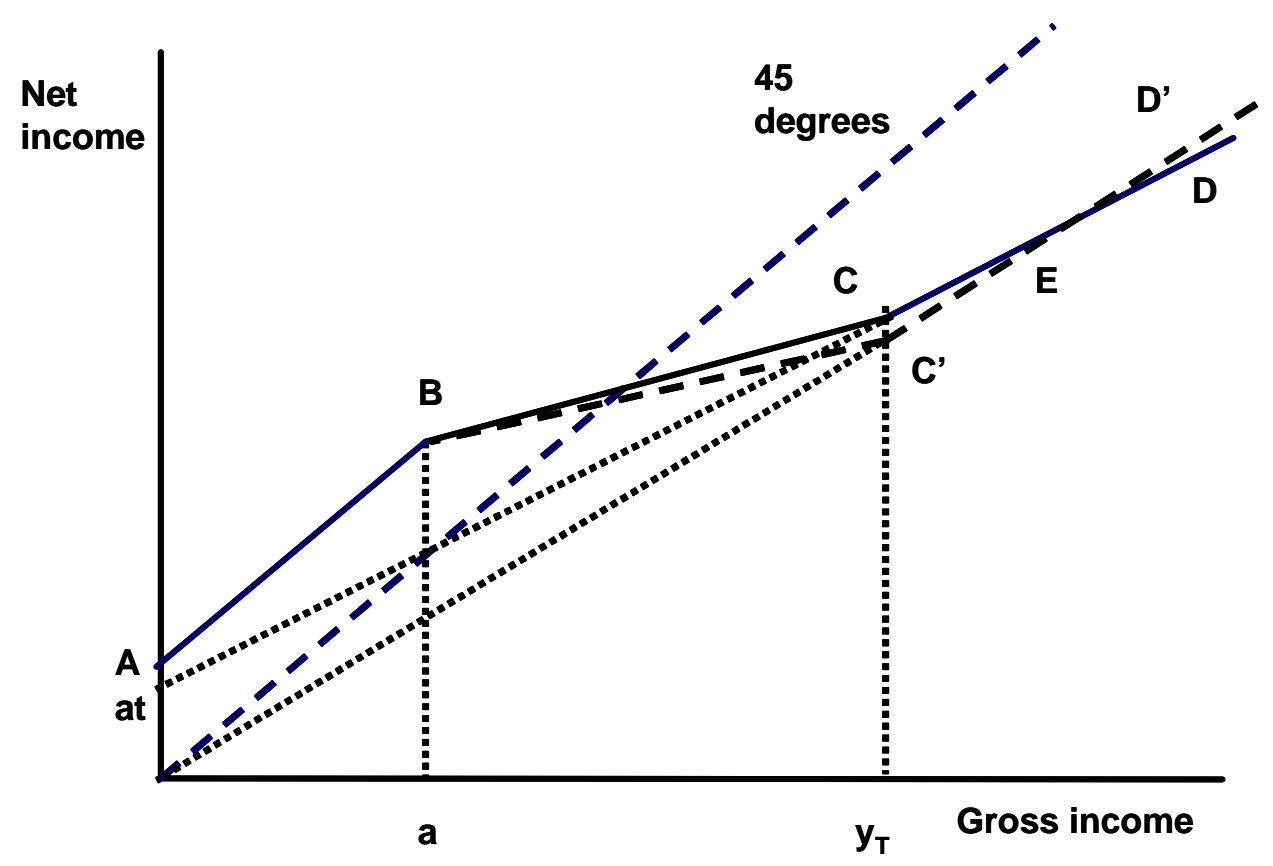

Figure 2:

Hence, despite the simplicity of the structure described above, it is not easy to design policy changes involving elimination of the tax-free threshold which are both revenue and distribution neutral. Furthermore, arguments for cutting the threshold are often accompanied by proposals for flattening the income tax rate structure, adding a further complication. Practical policy analysis requires the use of a behavioural microsimulation model, capable of dealing with the full complexity of the many elements of the tax and transfer system and the considerable degree of population heterogeneity, as well as labour supply behaviour. It is also useful to consider a range of implications of the policy changes for which summary measures can be computed. This provides information which people can use to form their own judgements.

\section{Description of Four Hypothetical Policy Changes}

Four alternative policy changes are examined here, each involving the elimination of the tax-free threshold. In finding the (approximately) revenue neutral tax rates, a process of trial and error was necessary. Only integer tax rates were considered. ${ }^{10}$ Adjustments were

\footnotetext{
${ }^{10}$ The costs of reducing separately each of the marginal tax rates by one percentage point were found to be approximately 1.4 billion dollars for the 17 per cent tax rate, 1.5 billion dollars for the 30 per cent tax
} 
made to the rates, rather than the tax thresholds. Detailed descriptions of each of the four policy changes are given in this section. The income tax structures and other features of the four policies are listed in Table 1, which gives the marginal tax rates applying between the relevant thresholds in the current structure and in the four alternative policies considered. These involve adjustments to the Low Income Tax Offset and Pension Rebate, the details of which are given in Appendix B.

Table 1: Marginal Tax Rates (Per Cent) and Other Features of Each Policy

\begin{tabular}{llllllr}
\hline & Annual income range (in AU\$) & Initial & \multicolumn{4}{c}{ Rates in policy: } \\
& tax rate & 1 & 2 & 3 & 4 \\
\hline 1 & $0-6000$ & 0 & 17 & 17 & 17 & 17 \\
2 & $6000-21600$ & 17 & 17 & 17 & 17 & 17 \\
3 & $21600-52000$ & 30 & 27 & 28 & 30 & 29 \\
4 & $52000-62500$ & 42 & 42 & 38 & 30 & 29 \\
5 & over 62500 & 47 & 47 & 47 & 31 & 30 \\
\hline Availability of additional features: & & & & & \\
$\quad$ Extended Low Income Tax Offset & & yes & yes & no & no \\
\multicolumn{2}{l}{ Pension Rebate top-up } & & no & yes & no & no \\
\hline
\end{tabular}

\subsection{Policy 1}

First, the tax-free threshold is eliminated and everyone earning less than $\$ 21,600$ in 2003/04 is compensated with an additional Low Income Tax Offset of $\$ 1,020$ (added to the $\$ 235$ that was available in 2003/04). This policy corresponds to going from Figure 1 to Figure 2 in Section 2. This off-set of $\$ 1,020$ corresponds to 17 per cent of $\$ 6,000$, which under Policy 1 is paid in additional tax. The remaining excess revenue collected from the higher-income earners is used to reduce the middle income tax rate from 30 to 27 per cent. This policy change is designed to be approximately revenue neutral under fixed labour supply. Assuming fixed labour supply, the amount of Pension Rebates decreases by $\$ 19.6$ million for couples. Furthermore, 63,000 fewer individuals receive it. ${ }^{11}$ This arises from the fact that unlike other rebates, excess Pension Rebate (relative to income tax payable) can be transferred from one partner to the other within a couple family. This is done without taking other rebates

rate, 200 million dollars for the 42 per cent tax rate and 500 million dollars for the 47 tax rate. These are only indicative values at the margin and they assume fixed labour supply. The cost of further reducing the marginal tax rates is not expected to be linear.

${ }^{11}$ These aggregate amounts are obtained by multiplying the sample numbers by their sample weights, provided by the SIHC. 
into account. ${ }^{12}$ Based on the 2003/04 Survey of Income and Housing Costs (SIHC) sample, 127,000 persons on an individual gross income below $\$ 21,600$ are expected to experience a decrease in their individual net income following the decrease in their Pension Rebate. ${ }^{13}$ This is due to the fact that less Pension Rebate can be transferred to them by their partner after the tax increase.

Although some individuals are expected to be worse off after the elimination of the taxfree threshold, the fact that as many as 127,000 of them would have an individual income below $\$ 21,600$ is an unexpected result. This is of concern because the aim of this policy change is to eliminate the tax-free threshold, while making sure low-income earners are fully compensated through the extension of the Low Income Tax Offset. This is an example of the type of interaction between tax and benefit structures that is not immediately obvious when considering separate components.

\section{$3.2 \quad$ Policy 2}

The second policy change is a small variation on Policy 1 which attempts to compensate for the reduction in the Pension Rebate for some low-income couples under Policy 1. It is difficult to compensate the pension recipients who lose income without overcompensating other income units or applying arbitrary changes. In Policy 2, the Low Income Tax Offset is increased as in Policy 1. In addition, the extra revenue generated from the elimination of the tax-free threshold is used to provide low-income partnered pension recipients with a Pension Rebate top-up, even though this means some other pension recipients are overcompensated as a result. The Pension Rebate, which is $\$ 304$ per year for couples, is increased by $\$ 1,020$ to compensate them. This benefits only partnered pension recipients. The remaining extra revenue is less than in Policy 1. Therefore, the middle income tax rate can only be reduced from 30 to 28 per cent. The remaining extra revenue is enough to lower the 42 per cent tax rate to 38 per cent. Again, the policy change is designed to be approximately revenue neutral under fixed labour supply.

\subsection{Policy 3}

The third policy change considers the elimination of the tax-free threshold accompanied by a reduction in the top two tax rates without increasing the Low Income Tax Offset. The

\footnotetext{
${ }^{12}$ See Appendix B for details. For details of the wide range of benefits in Australia, see Australian Government Department of Family and Community Services (2004). For details on taxes and rebates, see Australian Taxation Office (2006).

${ }^{13}$ The unweighted number in the SIHC is 187.
} 
42 per cent tax rate is reduced to 30 per cent and the 47 per cent tax rate is reduced to 31 per cent. This ensures that the policy change is approximately revenue neutral under fixed labour supply. Only high-income earners benefit from these tax cuts and the amount provided is unbounded, depending only on taxable income. As a result, very high income earners could be compensated by much more than they lost as a result of the elimination of the tax-free threshold.

\subsection{Policy 4}

The simulation results presented below show that, although Policy 3 is revenue neutral with fixed labour supply, the allowance for labour supply responses produces a substantial increase in total net revenue. This is because Policy 3 generates a substantial increase in labour supply, which translates into a large increase in net government revenue. In Policy 4, this extra revenue is used to reduce the three top income tax rates further, so that revenue neutrality is restored after allowing for labour supply responses. The 30 and 42 per cent tax rates are each reduced to 29 per cent and the 47 per cent tax rate is reduced to 30 per cent.

\section{Simulation Results}

The Melbourne Institute Tax and Transfer Simulator (MITTS) is used in this section to examine the effects of the hypothetical policy changes described above: see Appendix A for a brief summary of the model. The SIHC for 2003/2004 was used as the database in the analyses in this paper. Hence the tax and benefit changes examined apply to rates and thresholds in that year. The main aggregate summary measures are reported in subsection 4.1, and subsections 4.2 and 4.3 consider labour supply and welfare changes respectively.

\subsection{Summary of Aggregate Effects}

Table 2 summarises the aggregate results for each of the four policies examined, separately for four demographic groups. Separate econometric estimates of preference functions are available within MITTS for each of the demographic groups. For couples, the first amount for the average hours change relates to the male partner while the second amount is for the female partner.

Aggregate effects of the policy changes are calculated by adding all equivalent variations $(\mathrm{EV})$, compensating variations $(\mathrm{CV})$ and net incomes across all income units, using the 
Table 2: Summary of Aggregate Results (Million Dollars per Year)

\begin{tabular}{|c|c|c|c|c|c|}
\hline & Couples & $\begin{array}{r}\text { Single } \\
\text { men }\end{array}$ & $\begin{array}{r}\text { Single } \\
\text { women }\end{array}$ & $\begin{array}{r}\text { Single } \\
\text { parents }\end{array}$ & All \\
\hline \multicolumn{6}{|l|}{ Policy 1} \\
\hline \multicolumn{6}{|l|}{ Change in: } \\
\hline Net govt revenue (fixed labour supply) & 92 & -32 & -38 & -9 & 13 \\
\hline Net govt revenue (variable lab. sup.) & 61 & -29 & -33 & 0 & -1 \\
\hline Average hours (in hours per week) & $0.00 / 0.00$ & 0.01 & 0.01 & 0.05 & 0.01 \\
\hline Aggregate net income & -130 & 30 & 37 & 18 & -44 \\
\hline Compensating variation & 91 & -32 & -38 & -9 & 11 \\
\hline Equivalent variation & 91 & -32 & -38 & -9 & 12 \\
\hline Diff b/w net inc change and EV (in \%) & -30.3 & 6.3 & 2.8 & -52.2 & -73.9 \\
\hline \multicolumn{6}{|l|}{ Policy 2} \\
\hline \multicolumn{6}{|l|}{ Change in: } \\
\hline Net govt revenue (fixed labour supply) & -113 & 86 & 54 & 12 & 40 \\
\hline Net govt revenue (variable lab. sup.) & -163 & 69 & 47 & -5 & -53 \\
\hline Average hours (in hours per week) & $-0.03 /-0.07$ & -0.02 & -0.01 & -0.03 & -0.01 \\
\hline Aggregate net income & 41 & -112 & -68 & -20 & -159 \\
\hline Compensating variation & -119 & 86 & 54 & 11 & 33 \\
\hline Equivalent variation & -118 & 86 & 54 & 12 & 34 \\
\hline Diff b/w net inc change and EV (in \%) & 187.2 & -22.7 & -20.3 & -43.1 & -78.8 \\
\hline \multicolumn{6}{|l|}{ Policy 3} \\
\hline \multicolumn{6}{|l|}{ Change in: } \\
\hline Net govt revenue (fixed labour supply) & $-1,595$ & 573 & 824 & 372 & 174 \\
\hline Net govt revenue (variable lab. sup.) & 0 & 910 & 1,023 & 419 & 2,352 \\
\hline Average hours (in hours per week) & $0.30 /-0.05$ & 0.28 & 0.24 & 0.13 & 0.17 \\
\hline Aggregate net income & 4,477 & -25 & -516 & -319 & 3,617 \\
\hline Compensating variation & $-2,108$ & 573 & 807 & 367 & -362 \\
\hline Equivalent variation & $-1,868$ & 573 & 837 & 374 & -84 \\
\hline Diff $\mathrm{b} / \mathrm{w}$ net inc change and EV (in \%) & -58.3 & 2165.7 & 62.1 & 17.4 & -97.7 \\
\hline \multicolumn{6}{|l|}{ Policy 4} \\
\hline \multicolumn{6}{|l|}{ Change in: } \\
\hline Net govt revenue (fixed labour supply) & $-3,302$ & 246 & 637 & 319 & $-2,100$ \\
\hline Net govt revenue (variable lab. sup.) & $-1,574$ & 611 & 850 & 391 & 278 \\
\hline Average hours (in hours per week) & $0.34 / 0.00$ & 0.32 & 0.26 & 0.22 & 0.21 \\
\hline Aggregate net income & 6,536 & 362 & -302 & -244 & 6,352 \\
\hline Compensating variation & $-3,875$ & 246 & 618 & 313 & $-2,699$ \\
\hline Equivalent variation & $-3,597$ & 246 & 652 & 322 & $-2,377$ \\
\hline Diff b/w net inc change and EV (in \%) & -45.0 & -167.9 & 116.1 & 31.8 & -62.6 \\
\hline
\end{tabular}


survey weights provided with the SIHC data to obtain population level results. A positive value for the compensating or equivalent variation indicates a welfare loss. In terms of social evaluations, the focus on aggregate amounts can be regarded as equivalent to the assumption of zero relative inequality aversion.

The results show that Policies 1 and 2 imply very small changes. This is because lowincome households are almost fully compensated by the additional Low Income Tax Offset. As a result, their labour supply responses are negligible and both policy changes are approximately revenue neutral under both fixed and flexible labour supply assumptions. In Policy 1, couples appear to be the only demographic group losing from the policy change in terms of aggregate net income and welfare. As explained in Section 4.1.1, this is due to the Pension Rebate being held constant. In addition, they are more likely to be on a higher income than other groups and are therefore less likely to be fully compensated. By contrast, couples are the only demographic group to see an increase in their aggregate net income and welfare under Policy 2 because they are the only demographic group to benefit from the increase in the Pension Rebate (and some couples are actually overcompensated). In addition, they also benefit more from the reduction in the fourth tax rate, since they tend to have higher incomes than other demographic groups.

The results for Policies 3 and 4 show that labour supply responses are expected to be substantial if the elimination of the tax-free threshold is accompanied by reductions in the top tax rates instead of an increase in the Low Income Tax Offset. Labour supply responses are discussed in more detail in the next subsection. Following the large increase in labour supply, Policy 3, which is approximately revenue neutral under fixed labour supply, leads to a significant increase in net government revenue. Aggregate net income and welfare increase for couples but other demographic groups are worse off after the policy change (the only exception is an increase in aggregate net income for single men under Policy 4). This indicates that couples benefit more than other demographic groups from the decreases in the top tax rates.

Summary information regarding winners and losers by income unit decile, while taking into account the predicted labour response, is reported in Table 3 for Policies 1 and 4 . There is a sharp contrast between Policy 1, in which low income households are compensated, and Policy 4, in which they are not compensated. Under Policy 1, virtually none of the income units in the bottom three deciles lose, while the proportion of losers goes up with income level. The elimination of the tax-free threshold is not entirely compensated by the tax cuts for high-income households under Policy 1. The net income gains for low-income households 
Table 3: Winners and Losers by Income Unit Decile

\begin{tabular}{|c|c|c|c|c|c|c|}
\hline \multirow[t]{2}{*}{ Decile $^{a}$} & \multicolumn{3}{|c|}{$\begin{array}{c}\text { Percentage of } \\
\text { population who: } \\
\text { Stay }\end{array}$} & \multicolumn{2}{|c|}{$\begin{array}{l}\text { Ave. change in adult- } \\
\text { equivalent (in } \$ / \text { year) }\end{array}$} & \multirow[t]{2}{*}{$\begin{array}{r}\text { Number of } \\
\text { individuals } \\
(000 \mathrm{~s})\end{array}$} \\
\hline & $\operatorname{Lose}^{b}$ & equal & $\mathrm{Win}^{b}$ & Net inc & $\mathrm{EV}$ & \\
\hline \multicolumn{7}{|l|}{ Policy 1} \\
\hline 1 & 0.0 & 80.3 & 19.7 & 32.08 & -0.06 & 1,188 \\
\hline 2 & 0.0 & 90.2 & 9.8 & 10.95 & -0.25 & 1,569 \\
\hline 3 & 0.7 & 73.6 & 25.8 & 20.11 & -6.98 & 1,836 \\
\hline 4 & 11.8 & 37.1 & 51.1 & 2.61 & 3.93 & 2,322 \\
\hline 5 & 28.9 & 10.4 & 60.7 & -5.80 & 7.82 & 2,207 \\
\hline 6 & 33.1 & 4.0 & 62.9 & 38.89 & -38.81 & 2,122 \\
\hline 7 & 39.7 & 1.2 & 59.1 & 21.26 & -28.02 & 2,204 \\
\hline 8 & 48.7 & 1.1 & 50.1 & 1.55 & -13.23 & 2,108 \\
\hline 9 & 68.3 & 2.5 & 29.2 & -51.64 & 28.31 & 1,973 \\
\hline 10 & 89.2 & 0.4 & 10.4 & -102.31 & 71.15 & 1,986 \\
\hline Total & 34.1 & 25.7 & 40.3 & -4.45 & 1.96 & 19,516 \\
\hline \multicolumn{7}{|l|}{ Policy 4} \\
\hline 1 & 53.1 & 38.6 & 8.3 & -269.68 & 481.07 & 1,188 \\
\hline 2 & 61.7 & 36.8 & 1.6 & -169.05 & 222.59 & 1,569 \\
\hline 3 & 77.8 & 19.5 & 2.7 & -349.93 & 456.68 & 1,836 \\
\hline 4 & 91.7 & 4.4 & 3.9 & -393.27 & 610.18 & 2,322 \\
\hline 5 & 85.4 & 0.8 & 13.8 & -432.04 & 679.14 & 2,207 \\
\hline 6 & 77.0 & 0.2 & 22.9 & -131.86 & 502.35 & 2,122 \\
\hline 7 & 71.4 & 0.0 & 28.6 & 62.55 & 308.12 & 2,204 \\
\hline 8 & 66.4 & 0.1 & 33.5 & 208.28 & 130.62 & 2,108 \\
\hline 9 & 48.5 & 0.4 & 51.1 & 917.52 & -547.99 & 1,973 \\
\hline 10 & 13.7 & 0.2 & 86.1 & $5,668.39$ & $-5,222.93$ & 1,986 \\
\hline Total & 66.1 & 7.9 & 26.2 & 526.28 & -243.87 & 19,516 \\
\hline \multicolumn{7}{|l|}{ Notes: } \\
\hline \multicolumn{7}{|c|}{$\begin{array}{l}\text { a) Income unit deciles are based on net income unit income per adult } \\
\text { equivalent (before the policy change). } \\
\text { b) Winners are individuals whose net income unit income per adult equivalent } \\
\text { goes up by more than } \$ 1 \text { per year. Likewise, losers experience a decrease in } \\
\text { their net income unit income per adult equivalent of more than } \$ 1 \text { per year. }\end{array}$} \\
\hline
\end{tabular}


are achieved through an increase in labour supply (see the next subsection), which explains the limited welfare gains. By contrast, the decrease in net income for high-income households is partly caused by a reduction in labour supply, which limits their welfare losses.

The picture is quite different under Policy 4. A large number of low-income households lose from the policy change in terms of net income, because they are no longer compensated through an increase in the Low Income Tax Offset. Furthermore, the reduction in net income for households in the bottom deciles underestimates their welfare loss due to the increase in labour supply. The main winners are high-income households. They benefit the most from the reductions in the top tax rates. The gains are particularly large for the households belonging to the top decile.

\subsection{Labour Supply Response}

Table 4 summarises the labour supply responses by males and females for Policies 1 and 4. Under Policy 1, the increase in the labour supply of low-income households is influenced mainly by the reduction in the middle income tax rate from 30 to 27 per cent. For higherincome deciles this effect is likely to be offset by the impact of the elimination of the tax-free threshold, as the additional rebate is withdrawn at a rate of 4 per cent. Hence, so that the proportions of individuals reducing their labour supply become larger than the proportions of those increasing their labour supply. Middle-income households also face a higher effective marginal tax rate since the increased Low Income Tax Offset is tapered out over a larger range of their income.

Under Policy 4, the increase in the labour supply of low-income households is a result of the uncompensated elimination of the tax-free threshold, which has a direct negative impact on their net income. Moving up in the income distribution, both decreases and increases in labour supply arise for large proportions of the population. The decrease in tax rates means that at high income levels, the income effect allows individuals to maintain their level of net income while working fewer hours. However, there is a substitution effect leading to an increase in labour supply due to the lower marginal tax rates. The combination of these two effects leads to the mixed picture regarding the labour supply responses of high-income households presented in the table.

\subsection{Inequality and Welfare Changes}

The four policies discussed in this analysis are also expected to affect income distribution and welfare; in particular, Policy 3 and Policy 4 appear likely to affect these two measures. 
Table 4: Labour Supply Responses by Income Unit Decile

\begin{tabular}{|c|c|c|c|c|c|c|c|c|}
\hline \multirow[b]{3}{*}{ Decile } & \multicolumn{4}{|c|}{ Men } & \multicolumn{4}{|c|}{ Women } \\
\hline & \multicolumn{3}{|c|}{$\begin{array}{l}\text { Change in hours } \\
\text { (per cent) }\end{array}$} & \multirow{2}{*}{$\begin{array}{r}\text { Number } \\
(000 \mathrm{~s})\end{array}$} & \multicolumn{3}{|c|}{$\begin{array}{l}\text { Change in hours } \\
\text { (per cent) }\end{array}$} & \multirow{2}{*}{$\begin{array}{r}\text { Number } \\
(000 \mathrm{~s})\end{array}$} \\
\hline & Less & None & more & & Less & None & more & \\
\hline \multicolumn{9}{|l|}{ Policy 1} \\
\hline 1 & 0.0 & 81.5 & 18.5 & 552 & 0.0 & 85.7 & 14.3 & 524 \\
\hline 2 & 0.0 & 94.3 & 5.7 & 601 & 0.1 & 94.2 & 5.7 & 772 \\
\hline 3 & 0.4 & 93.8 & 5.8 & 574 & 0.3 & 90.1 & 9.6 & 754 \\
\hline 4 & 5.5 & 89.0 & 5.5 & 700 & 1.3 & 89.7 & 9.0 & 833 \\
\hline 5 & 9.9 & 85.9 & 4.3 & 701 & 3.1 & 88.0 & 8.9 & 779 \\
\hline 6 & 9.2 & 87.8 & 3.1 & 729 & 5.2 & 87.4 & 7.4 & 713 \\
\hline 7 & 14.7 & 81.9 & 3.4 & 756 & 11.7 & 79.4 & 8.9 & 739 \\
\hline 8 & 16.0 & 80.7 & 3.3 & 805 & 13.8 & 78.7 & 7.5 & 750 \\
\hline 9 & 21.7 & 75.0 & 3.2 & 811 & 19.6 & 74.0 & 6.4 & 744 \\
\hline 10 & 18.1 & 79.0 & 2.9 & 891 & 20.3 & 76.1 & 3.6 & 753 \\
\hline Total & 10.6 & 84.3 & 5.1 & 7,122 & 7.7 & 84.4 & 8.0 & 7,361 \\
\hline \multicolumn{9}{|l|}{ Policy 4} \\
\hline 1 & 3.4 & 53.1 & 43.5 & 552 & 1.3 & 66.1 & 32.7 & 524 \\
\hline 2 & 0.9 & 88.1 & 11.0 & 601 & 0.6 & 93.0 & 6.4 & 772 \\
\hline 3 & 2.7 & 78.5 & 18.8 & 574 & 3.1 & 82.1 & 14.8 & 754 \\
\hline 4 & 8.4 & 68.5 & 23.1 & 700 & 7.6 & 76.8 & 15.6 & 833 \\
\hline 5 & 12.2 & 60.4 & 27.4 & 701 & 16.3 & 58.8 & 24.8 & 779 \\
\hline 6 & 12.9 & 54.0 & 33.1 & 729 & 17.5 & 55.5 & 27.0 & 713 \\
\hline 7 & 22.0 & 43.8 & 34.2 & 756 & 28.0 & 42.5 & 29.4 & 739 \\
\hline 8 & 23.5 & 45.4 & 31.2 & 805 & 30.4 & 40.5 & 29.1 & 750 \\
\hline 9 & 19.0 & 46.3 & 34.7 & 811 & 29.2 & 43.5 & 27.2 & 744 \\
\hline 10 & 22.1 & 52.1 & 25.9 & 891 & 31.9 & 45.8 & 22.3 & 753 \\
\hline Total & 13.8 & 57.6 & 28.5 & 7,122 & 16.9 & 60.6 & 22.5 & 7,361 \\
\hline
\end{tabular}


As explained in Appendix A, MITTS uses a discrete hours labour supply model. Appendix C briefly describes the method of computing welfare changes for each individual in a discrete hours context. ${ }^{14}$ The behavioural simulations produce a frequency distribution of postreform hours for each individual, conditional on the individual's optimal pre-reform hours being equal to observed (discretised) hours. This flows on to the welfare calculation, so that consequently a frequency distribution of welfare changes is obtained for each individual, from which the expected welfare change is then calculated as the arithmetic mean value. Again, this is the mean of a conditional distribution.

This information can be used to obtain excess tax burdens and marginal welfare costs for each income unit. Direct comparisons of welfare changes and net income changes can also be made. ${ }^{15}$ Population-level evaluations of welfare necessarily involve value judgements, so that a decision must be made regarding the social evaluation method. Any evaluation for a broad group of income units necessarily involves comparisons of units of different size and composition. Value judgements concern three aspects: the welfare metric, the definition of the unit of analysis and the form of the social welfare function to be used. The latter is closely related to value judgements regarding inequality aversion and the implied inequality measure. Different values of inequality aversion are used in the analyses in this paper. The reported results are based on the use of money metric utility per adult equivalent, using the Whiteford equivalence scales reported by Binh and Whiteford (1990), and using the individual as the unit of analysis. ${ }^{16}$

The steps in the social evaluation are as follows. For each income unit, the initial money metric utility, $M_{0}$, is obtained, using pre-reform taxes as 'reference prices'; this is equal to full income under the pre-reform system. Given the approach used to calculate $E V$ and $C V$, taking into account the non-linearity and non-convexity of the budget constraint, $M_{0}$ is calculated in a way that is consistent with this approach. For each income unit, the net income at 80 hours of work by all adult members of the income unit under pre-reform taxes is calculated. Assuming that 80 hours is the maximum number of hours that can be worked per week, this net income represents full income for the income unit. Then, given the expected equivalent variation, $E V$, resulting from the reform, expected post-reform money metric utility is computed as $M_{1}=M_{0}-E V$.

\footnotetext{
${ }^{14}$ More detail on the approach can be found in Creedy and Kalb (2005b) and in Creedy, Hérault and Kalb (2007).

${ }^{15}$ For individuals whose labour supply is fixed, for example those who are not in the labour market, the money measure of the welfare change is equal to the net income change.

${ }^{16} \mathrm{It}$ is recognised that the results can be influenced by the choice of adult equivalence scales and unit of analysis, but these are of secondary importance here.
} 
For each income unit, the adult equivalent size, $s$, is obtained using equivalence scales, and this in turn is used to compute money metric utility per adult equivalent, $m_{j i}$, where $j$ refers to the tax structure and $i$ refers to the income unit. The distributions of pre-reform and post-reform money metric can be used to calculate social evaluations.

In computing inequality measures with the individual as the unit of analysis, each value of $m_{j i}$ is weighted by the actual number of persons in the income unit, $n_{i}$. This paper uses Atkinson's inequality measure, $A(\varepsilon)$, where $\varepsilon$ is the degree of relative inequality aversion. The inequality measure is expressed as 1 minus the ratio of the equally distributed equivalent value to the arithmetic mean. The equally distributed equivalent value is the value which, if obtained by everyone, gives the same social welfare as the actual distribution. Using an additive welfare function based on constant relative inequality aversion, the equally distributed equivalent value, $y_{e d e}$, is in general, for a set of values $y_{i}$, for $i=1, \ldots, N$, equal to:

$$
y_{\text {ede }}=\left(\frac{1}{N} \sum_{i} y_{i}^{1-\varepsilon}\right)^{1 /(1-\varepsilon)}
$$

In the present context an adjustment must be made for the weighting by the number of persons in each household. Results can be obtained for a range of inequality aversion parameters, $\varepsilon$. Finally, social welfare in each system is obtained using the abbreviated welfare function, $W_{j}=\bar{m}_{j}(1-A(\varepsilon))$, which is associated with the Atkinson inequality measure (and where $\bar{m}_{j}$ is the arithmetic mean value of the money metric utility per adult equivalent, $\left.m_{j i}\right)$. It is then possible to compare results based on money metric utility with those obtained using net incomes in the social welfare function.

The first four columns in Table 5 provide information about the effects of the four policies on inequality, using a range of Atkinson measures and the Gini inequality index, based on both net income and the money metric measure of utility. As expected, the changes are fairly small under Policies 1 and 2. Only a minor decrease in inequality is observed, which is due to the reduction in net income for some high-income households. Note that the use of net income produces somewhat higher reductions in inequality than the use of money metric utility. This arises due to the failure to value leisure time in measures based on net income only. In contrast, the changes associated with Policies 3 and 4 are much more substantial. As expected, both policies generate large increases in inequality. For the same reason as in Policies 1 and 2, the use of net income produces higher increases in inequality than the use of money metric utility.

Table 5 shows that the magnitude of the percentage increases in Atkinson's index 
decreases with increasing relative inequality aversion. As the inequality aversion parameter decreases, the Atkinson index becomes more sensitive to changes in the upper end of the income (or money metric) distribution, where the changes are the largest in absolute terms. As a result, the changes in the Atkinson index become larger. This also explains why the Atkinson index is more sensitive to $\varepsilon$ in policies 3 and 4, where the top tax rates are lowered, resulting in the largest absolute changes at the upper end of the distribution. ${ }^{17}$

Table 5: Inequality and Social Welfare Measures

\begin{tabular}{|c|c|c|c|c|c|c|c|c|}
\hline & \multicolumn{3}{|c|}{ Atkinson's index } & \multirow[b]{2}{*}{ Gini } & \multirow{2}{*}{$\begin{array}{l}\text { Mean } \\
\text { value }\end{array}$} & \multicolumn{3}{|c|}{ Social Welfare } \\
\hline & $\varepsilon=0.2$ & $\varepsilon=0.8$ & $\varepsilon=1.4$ & & & $\varepsilon=0.2$ & $\varepsilon=0.8$ & $\varepsilon=1.4$ \\
\hline \multicolumn{9}{|l|}{ Pre-reform } \\
\hline Money metric & 0.0177 & 0.0630 & 0.1018 & 0.2186 & 55,972 & 54,980 & 52,444 & 50,273 \\
\hline Net income & 0.0267 & 0.1008 & 0.1669 & 0.2851 & 27,307 & 26,577 & 24,556 & 22,750 \\
\hline \multicolumn{9}{|l|}{ Post-reform } \\
\hline \multicolumn{9}{|l|}{ Policy 1} \\
\hline Money metric & 0.0177 & 0.0630 & 0.1017 & 0.2184 & 55,970 & 54,980 & 52,446 & 50,277 \\
\hline Change (\%) & -0.11 & -0.11 & -0.10 & -0.06 & 0.00 & 0.00 & 0.00 & 0.01 \\
\hline Net income & 0.0267 & 0.1004 & 0.1663 & 0.2845 & 27,303 & 26,575 & 24,561 & 22,761 \\
\hline Change (\%) & -0.35 & -0.35 & -0.34 & -0.18 & -0.02 & -0.01 & 0.02 & 0.05 \\
\hline \multicolumn{9}{|l|}{ Policy 2} \\
\hline Money metric & 0.0177 & 0.0630 & 0.1017 & 0.2184 & 55,967 & 54,977 & 52,444 & 50,275 \\
\hline Change (\%) & -0.12 & -0.12 & -0.12 & -0.08 & -0.01 & -0.01 & 0.00 & 0.01 \\
\hline Net income & 0.0266 & 0.1002 & 0.1661 & 0.2842 & 27,294 & 26,567 & 24,558 & 22,761 \\
\hline Change (\%) & -0.50 & -0.51 & -0.50 & -0.30 & -0.05 & -0.04 & 0.01 & 0.05 \\
\hline \multicolumn{9}{|l|}{ Policy 3} \\
\hline Money metric & 0.0194 & 0.0686 & 0.1100 & 0.2280 & 56,047 & 54,957 & 52,200 & 49,882 \\
\hline Change (\%) & 9.73 & 8.89 & 8.02 & 4.34 & 0.13 & -0.04 & -0.47 & -0.78 \\
\hline Net income & 0.0316 & 0.1158 & 0.1876 & 0.3061 & 27,632 & 26,759 & 24,432 & 22,447 \\
\hline Change (\%) & 18.02 & 14.92 & 12.42 & 7.39 & 1.19 & 0.69 & -0.50 & -1.33 \\
\hline \multicolumn{9}{|l|}{ Policy 4} \\
\hline Money metric & 0.0196 & 0.0691 & 0.1107 & 0.2289 & 56,216 & 55,116 & 52,331 & 49,991 \\
\hline Change (\%) & 10.47 & 9.64 & 8.76 & 4.75 & 0.44 & 0.25 & -0.22 & -0.56 \\
\hline Net income & 0.0319 & 0.1170 & 0.1895 & 0.3078 & 27,834 & 26,946 & 24,577 & 22,559 \\
\hline Change (\%) & 19.26 & 16.11 & 13.54 & 7.97 & 1.93 & 1.39 & 0.09 & -0.84 \\
\hline
\end{tabular}

Measures of social welfare, using the iso-elastic social welfare function associated with the

\footnotetext{
${ }^{17}$ On the other hand, if changes at the bottom end of the income range are larger than changes at the top end, the absolute percentage changes should increase with epsilon.
} 
use of the Atkinson inequality measure, are given in the last four columns of Table 5. Social welfare is virtually unchanged under Policies 1 and 2. There is a small decline for the lowest value of the inequality aversion parameter but at higher levels of relative inequality aversion, the slight decrease in inequality offsets the minor reduction in aggregate net income, which results in a very small increase in social welfare.

Similar to the effect on inequality, Policies 3 and 4 also generate much larger changes on social welfare. Both policies improve social welfare at the lowest level of relative inequality aversion and the improvements are highest for the measures based on net income. In contrast, social welfare decreases at the highest level of relative inequality aversion because the increase in net income (or money metric utility) no longer offsets the widening of the income distribution sufficiently.

Policy 4 increases social welfare more (or decreases it to a lesser extent) than Policy 3. This is due to the additional government expenditure in Policy 4, spending the additional government revenue generated by the increase in labour supply, due to the abolished taxfree threshold and reduced top tax rates, to reduce the top tax rates further. However, inequality also increases more under Policy 4, because middle- and high-income households benefit most from the further reduction in the tax rates, increasing the gap between them and low-income households.

\section{Conclusions}

This paper has examined the effects of four alternative policy changes, each involving the elimination of the tax-free threshold in Australia and designed to achieve approximate revenue neutrality, using the Melbourne Institute Tax and Transfer Simulator. A range of implications were examined, including labour supply responses to tax changes, and the effects of policy changes on inequality and social welfare.

The first two policies ensure that low-income individuals are fully compensated through an extension of the Low Income Tax Offset. In addition, the extra revenue raised from higher incomes as a result of the extension of the tax base was used to reduce the middle (marginal) income tax rate. Both policies were close to being both revenue neutral and distribution neutral, with only high-income households experiencing a decrease in net income. As a result of the small changes, labour supply incentives hardly changed and therefore labour supply remained nearly the same as before the policy change.

The third and fourth policies also eliminated the tax-free threshold and at the same time aimed to flatten the marginal tax rate structure. These policies did not compensate 
low-income individuals at all, but instead reduced the top tax rates. Again the policies were close to revenue neutral (the third policy under fixed labour supply and the fourth after allowing for labour supply responses) but, as expected, they were no longer distribution neutral. The lowest-income households are affected the most negatively, and some of the high-income households are much better off after the policy change. As a result of the large changes in net income, large labour supply responses are also observed. Both increases and decreases are predicted, with the average effect being an increase, and the predominant effect for low-income individuals also being an increase in labour supply. The cost of this increased labour supply is higher inequality and a decrease in social welfare when evaluated at medium to high levels of relative inequality aversion.

The results therefore demonstrate that it is possible to eliminate the tax-free threshold under approximate overall revenue and distribution neutrality, but that it is impossible to improve labour supply incentives at the same time. In fact, not much changes in the first two policies which are revenue and distribution neutral. In order to achieve improved incentives, either revenue or distribution neutrality has to be sacrificed. 


\section{Appendix A: The Melbourne Institute Tax and Transfer Simulator}

This appendix provides a brief description of the Melbourne Institute Tax and Transfer Simulator (MITTS), a behavioural microsimulation model of direct tax and transfers in Australia. Since the first version was completed in 2000, it has undergone a range of substantial developments. MITTS is based on the Australian Survey of Income and Housing Costs (SIHC), a representative sample of the Australian population, containing detailed information on labour supply and income from different sources, in addition to a variety of background characteristics of individuals and households. All results are aggregated to the population level using the household weights provided with SIHC. Pre-reform net incomes at alternative hours levels are based on the MITTS calculation of entitlements, not the actual receipt. Furthermore, MITTS applies only income tests, as there is at present no asset imputation in the model. All major social security payments and income taxes are included, ensuring a reasonable approximation to net income.

MITTS consists of two components. MITTS-A is the arithmetic tax and benefit modelling component and provides, using the wage rate of each individual, the budget constraints that are crucial for the analysis of behavioural responses to tax changes. For those individuals in the data set who are not working, an imputed wage is obtained. MITTS-B examines the effects of any specified tax reform, allowing individuals to adjust their labour supply. Behaviour is based on quadratic preference functions where the parameters are allowed to vary with individuals' characteristics. Individuals are considered as being constrained to select from a discrete set of hours levels. For singles, 11 discrete points are distinguished. For couples, two sets of discrete labour supply points are used. The female hours distribution covers a wider range of part-time and full-time hours than the male distribution, which is mostly divided between non-participation and full-time work. Therefore, women's labour supply is divided into 11 discrete points, whereas men's labour supply is represented by just 6 points. The joint labour supply of couples is estimated simultaneously, unlike a popular approach in which female labour supply is estimated with the spouse's labour supply taken as exogenous. Thus for couples there are 66 possible joint labour supply combinations.

Simulations are probabilistic, as utility at each hours level is the sum of a deterministic component (depending on hours worked and net income) and a random component. Hence MITTS generates a probability distribution over the discrete hours levels. The selfemployed, disabled, students and those over 65 have their labour supply fixed at observed 
hours. Simulations begin by recording the discrete hours level for each individual that is closest to the observed hours level. The deterministic component of utility is obtained using the parameter estimates of the quadratic preference function. To generate the random component, a draw is taken from the distribution of the error term for each hours level (an Extreme Value Type I distribution). The utility-maximising hours level is found by adding the two components of utility for each hours level and choosing the hours with the highest utility. Draws from the error terms are taken conditionally on the observed labour supply; that is, they are taken in such a way that the optimal pre-reform labour supply is equal to the actually observed labour supply. As a result, post-reform labour supply is simulated conditional on the observed pre-reform labour supply. A user-specified number of draws is produced.

For the post-reform analysis, the new net incomes cause the deterministic component of utility at each hours level to change, so using the same set of draws from the calibration stage, a new set of optimal hours of work is produced. This gives rise to a probability distribution over the set of discrete hours for each individual under the new tax and transfer structure. Post-reform labour supply is based on the average value over the draws. This is equivalent to calculating the expected hours of labour supply after the change, conditional on starting from the observed hours before the change. In computing tax and revenue levels, an expected value is also obtained after the policy change.

\section{Appendix B: Two Rebates}

In Australia, a number of rebates (or offsets) are available to reduce the tax payable for specific groups. The rebates can only be used to offset taxes that are payable; they cannot be paid. Rebates reduce the tax payable by a certain amount rather than the taxable income. This appendix discusses the two rebates that are most relevant in the four policy changes analysed in this paper: the Pension Rebate and the Low Income Tax Offset.

\section{B.1: The Low Income Tax Offset}

Individuals with annual taxable income below $\mathrm{AU} \$ 21,600$ are entitled to the Low Income Tax Offset (LITO). The maximum level of the rebate is AU $\$ 235$ per year and is reduced by 4 cents for every dollar of taxable income above the threshold. Denoting the individual's income by $y$, the annual amount of Low Income Tax Offset is calculated as:

$$
\begin{array}{rlrl}
\text { LITO } & =\$ 235 & & \text { if } y<\$ 21,600 \\
& =\max [0, \$ 235-0.04(y-\$ 21,600)] & \text { if } y \geq \$ 21,600
\end{array}
$$




\section{B2: The Pension Rebate}

All recipients of taxable social security and Veterans Affairs service pensions, including the parenting payment (single), may be eligible for the pensioner rebate. Once taxable income reaches a threshold of $y_{T}$ the rebate is shaded out at 12.5 cents for each dollar above the threshold. The maximum rebate level is calculated as the difference between the threshold level of income, $y_{T}$, and the tax-free (or first) threshold $y_{T F T}$ (AU $\$ 6,000$ per year) multiplied by the lowest marginal tax rate, $\tau_{L}(17$ per cent). Thus the maximum rebate, $\max P R$, is given by:

$$
\max P R=\tau_{L}\left(y_{T}-y_{T F T}\right)
$$

The threshold amount is the sum of the maximum annual base pension payable, $P_{B}$, plus the income-free area for the pension per person, $P_{F} / n$ (where $n$ is 1 or 2 , depending on whether the individual is single or partnered). These two amounts differ depending on the type of pension and the composition of the household. Thus:

$$
y_{T}=P_{B}+P_{F} / n
$$

The pensioner rebate is thus calculated as:

$$
\begin{aligned}
P R & =\max P R & & \text { if } y<y_{T} \\
& =\max \left[0, \max P R-0.125\left(y-y_{T}\right)\right] & & \text { if } y \geq y_{T}
\end{aligned}
$$

Partnered pensioners can transfer the unused portion of their rebate to their partner if the partner has a tax liability. However, the calculation of the unused portion of their rebate does not take the presence of other rebates into account. If the amount of the Pension Rebate is less than the amount of income tax to be paid, no transfer takes place.

In the first two policies, $y_{T F T}$ is kept at AU $\$ 6,000$ since the Low Income Tax Offset takes over the role of the tax free income range for low-income households. The tax rate in the first income range is in effect raised from 0 to 17 per cent, while keeping the first tax threshold, although there is no longer a tax rate change at this level. The problem under Policy 1 arises because low-income individuals transfer less rebate to their partners, since they start paying tax from the first dollar of earnings. Although the additional tax payment is compensated by the increased Low Income Tax Offset, the pension rebate calculation does not take into account this increased Low Income Tax Offset and assumes that the low-income individual pays enough tax to offset the Pension Rebate against. At the final stage of rebate calculation, when all rebates are added together, there is more rebate than tax payable for these low-income individuals. As a result, less than the full sum of rebates is paid out and 
the higher income partner does not benefit to the same extent as before from a transfer in the Pension Rebate, resulting in a decrease in net income.

\section{Appendix C: Welfare Changes in a Discrete Hours Frame- work}

Individuals are restricted to hours levels $h_{1}, \ldots, h_{H}$ and the utility function and net incomes at each point are known. The optimal number of hours is obtained by calculating utilities at $H$ points, each of which is treated as a corner solution. Let $U_{j}^{k}$ denote utility obtained from hours level $h_{k}$ and tax and transfer system $j$. Similar indices are used when referring to the corresponding virtual non-wage income, $\mu$, and virtual wages, $w$, except that an additional subscript is needed to refer to the discrete hours level to which the virtual values relate. ${ }^{18}$ Hence the virtual wage, $w_{0, j}^{k}$ is the slope of indifference curve $U_{0}^{k}$ at the discrete hours point $h_{j}$. Similarly, $\mu_{0, j}^{k}$ is the corresponding virtual non-wage income, which is represented by the intercept on the net income axis of the tangent to the indifference curve, $U_{0}^{k}$, at the discrete hours level $h_{j}$.

Consider Figure 3, where four discrete hours levels are available. The original optimal position is at point $\mathrm{A}$ on indifference curve, $U_{0}^{3}$, corresponding to $h_{3}$ hours of work. A tax reform causes the optimal position to shift to B on indifference curve $U_{1}^{2}$, involving $h_{2}$ hours of work. The virtual linear budget constraints associated with $\mathrm{A}$ and $\mathrm{B}$ are defined by the pairs $\left(\mu_{0,3}^{3}, w_{0,3}^{3}\right)$ and $\left(\mu_{1,2}^{2}, \mu_{1,2}^{2}\right)$ respectively. ${ }^{19}$ The standard compensating variation is the difference between the net incomes at points $\mathrm{D}$ and $\mathrm{B}$, but labour supply between $h_{1}$ and $h_{2}$ hours of work is not available, so $U_{0}^{3}$ cannot be reached. In addition, even if the labour supply point were available, the nonlinearity and nonconvexity of the budget constraint may make the actual compensation required at this point different from the distance between $\mathrm{D}$ and B. At $h_{2}$ hours of work, at least the difference between the net incomes at points $\mathrm{E}$ and $\mathrm{B}$ is required although it is not necessarily the minimum compensation needed when hours of work are allowed to vary over the discrete points available. It may be possible to work $h_{i} \neq h_{2}$ hours and reach indifference curve $U_{0}^{3}$ with a smaller increase to net income than the distance $\mathrm{BE}$.

The virtual wage corresponding to $h_{2}$ at point $\mathrm{E}$ on $U_{0}^{3}$, and $\mu_{0,2}^{3}$ represents the associated

\footnotetext{
${ }^{18}$ Any position can be regarded as being generated by a linear virtual constraint $c=w h+\mu$, where $c$ is consumption (assumed to be equal to net income).

${ }^{19}$ For each hours point, $h_{j}, c_{j}^{0}$ and $c_{j}^{1}$ can be determined, after which $U\left(c_{j}^{0}, h_{j}\right)$ can be calculated. Then $w_{0, i}^{i}$ is the virtual wage in the optimal point $h_{i}$ associated with utility level $U_{0}^{i}$ and $\mu_{0, i}^{i}=c_{i}^{0}-w_{0, i}^{i} h_{i}$.
} 


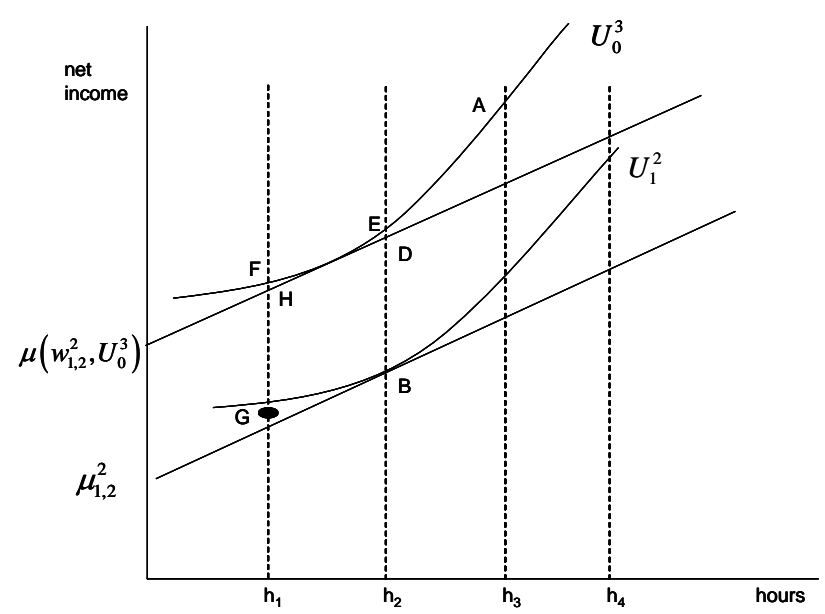

Figure 3: Compensating Variation in Discrete Hours Labour Supply Context

virtual income. ${ }^{20}$ To determine the compensating variation, the distance between the current budget constraint and net income required to reach the original utility level $U_{0}^{3}$ must be determined at all labour supply levels. For example, if net income at $h_{1}$ in system 1 is at point $\mathrm{G}$ (which is above the virtual linear budget constraint associated with $\mathrm{B}$ ), it is possible that the distance between $\mathrm{G}$ and $\mathrm{F}$ is smaller than that between $\mathrm{B}$ and E. Even if $\mathrm{G}$ were slightly below the virtual budget line through $\mathrm{B}$, it is possible for the compensating variation to be lower than if hours were fixed at $h_{2}$, depending on the distance $\mathrm{FH}$ compared with ED. Point $\mathrm{G}$ is the combination of net income on the actual budget constraint under the post-reform tax system and hours level $h_{1}$, so the indifference curve through this point is labelled $U_{1}^{1}$. At $\mathrm{G}$, the compensation required to reach $U_{0}^{3}$ is the length $\mathrm{GF}$, given by:

$$
\begin{aligned}
C V & =\left\{\mu_{0,1}^{3}+w_{0,1}^{3} h_{1}\right\}-\left\{\mu_{1,1}^{1}+w_{1,1}^{1} h_{1}\right\} \\
& =\left\{\mu_{0,1}^{3}-\mu_{1,1}^{1}\right\}+\left\{w_{0,1}^{3}-w_{1,1}^{1}\right\} h_{1}
\end{aligned}
$$

The appropriate compensation is the minimum of this type of difference, over all discrete hours points. This procedure requires only the calculation of net income corresponding to a specified hours level and indifference curve, for a limited number of different hours levels.

\footnotetext{
${ }^{20}$ Determine $c_{0,2}^{3}$ needed to reach $U_{0}^{3}$ in $h_{2}$ by solving for $c$ in $U\left(c, h_{2}\right)=U_{0}^{3}$ and then use $\mu_{0,2}^{3}=$ $c_{0,2}^{3}-w_{0,2}^{3} h_{2}$.
} 


\section{References}

[1] Australian Government Department of Family and Community Services (2004) Annual Report 2003-04, Canberra, available on http://www.facsia.gov.au/annualreport/2004/toc.htm.

[2] Australian Taxation Office (2006) Taxation Statistics 2003-04 A summary of tax returns for the 2003-04 income year and collections for the 2004-05 financial year, Canberra, available on http://www.ato.gov.au/content/downloads/70906_2004TAXSTATS.pdf.

[3] Binh, T. N. and Whiteford, P. (1990) Household equivalence scales: new Australian estimates from the 1984 Household Expenditure Survey. Economic Record, 66, pp. 221-234.

[4] Creedy, J. and Kalb, G. (2005a) Discrete hours labour supply modelling: specification, estimation and simulation. Journal of Economic Surveys, 19, pp. 697-734.

[5] Creedy, J. and Kalb, G. (2005b) Measuring welfare changes in labour supply models. Manchester School, 73, pp. 664-685.

[6] Creedy, J. and Kalb, G. (2006) Labour Supply and Microsimulation. Cheltenham: Edward Elgar.

[7] Creedy, J., Duncan, A.S., Harris, M., and Scutella, R. (2002) Microsimulation Modelling of Taxation and The Labour Market: The Melbourne Institute Tax and Transfer Simulator. Cheltenham: Edward Elgar.

[8] Creedy, J., Hérault, N. and Kalb, G. (2007) Comparing Welfare Change Measures with Income Change Measures in Behavioural Policy Simulations. Melbourne Institute of Applied Economic and Social Research Working Paper No. 21/07. The University of Melbourne.

[9] Freebairn, J. (1998) Efficiency Issues. In The Tax Reform Debate (ed. by P. Abelson), pp. 46-70. Sydney: Allen and Unwin.

[10] Hicks, U.K. (1946) Public Finance. Cambridge: Cambridge University Press.

[11] Kalb, G. and Lee, W.-S. (2007) Wage and Labour Force Participation in Australia: Accounting for Categorised Observations on Wages. Final Report for Treasury. 
[12] Kalb, G. and Lee, W.-S. (2008) Labour Supply in the Australian Population: Using Data from 1999 to 2004. Final Report for Treasury.

[13] Saunders, P. (2006) Taxploitation: The Case for Income Tax Reform. Sydney: Centre for Independent Studies.

[14] Saunders, P. and Maley, B. (2006) Tax Reform to Make Work Pay. In Taxploitation: The Case for Income Tax Reform (ed. by P. Saunders), pp. 104-122. Sydney: Centre for Independent Studies.

[15] Stevens, R. (1990) Flattening the tax rate scale in New Zealand. In Flattening the Tax Rate Schedule (ed. by J.G. Head and R. Krever). Melbourne: Longman.

[16] Veit-Wilson, J. (1999) The tax threshold: policy, principles, and poverty. Twentieth Century British History, 10, pp. 218-234. 